\title{
PRODUÇÃO DE MUDAS DE Tectona grandis EM SUBSTRATOS FORMULADOS COM BIOSSÓLIDO
}

\author{
Paulo André Trazzi ${ }^{1 *}$, Marcos Vinicius Winckler Caldeira² ${ }^{2}$ Edvaldo Fialho dos Reis², Aderbal Gomes da Silva ${ }^{2}$
}

*Autor para correspondência: patrazzi@hotmail.com

\begin{abstract}
RESUMO: Os resíduos industriais e urbanos podem ser utilizados como fonte de nutrientes visando contribuir para a redução dos custos de produção de mudas florestais e também podem ser uma saída para reduzir ou solucionar problemas ambientais. O presente trabalho teve por objetivo avaliar a utilização de biossólido como substrato na produção de mudas de Tectona grandis. As mudas foram produzidas em tubetes com capacidade volumétrica de $280 \mathrm{~cm}^{3}$, em substratos formulados com biossólido (BIO) associado à casca de arroz carbonizada $(\mathrm{CAC})$ ou à fibra de coco triturada $(\mathrm{FC})$ nas proporções 80:20, 60:40, 40:60, 20:80 (v:v), e também com $100 \%$ de $\mathrm{BIO}$, totalizando nove tratamentos submetidos à comparação do tratamento testemunha (substrato comercial). Os substratos formados foram submetidos às análises químicas e físicas. Noventa dias após a repicagem, foram analisadas as seguintes características biométricas: altura da parte aérea, diâmetro do coleto, massa seca da parte aérea e radicular e o índice de qualidade de Dickson. Os resultados indicaram que as mudas produzidas nos substratos formulados com BIO e CAC apresentaram as maiores médias de altura e massa seca da parte aérea, enquanto que as produzidas com BIO e FC obtiveram as maiores médias de diâmetro do coleto. Para a produção de mudas de Tectona grandis, é aconselhável a utilização de um substrato com proporções de 60 ou $80 \%$ de biossólido quando associado à fibra de coco triturada; e de $80 \%$ de biossólido quando associado à casca de arroz carbonizada.
\end{abstract}

Palavras-chave: lodo de esgoto, teca, características biométricas.

\section{SEEDLING PRODUCTION OF Tectona grandis ON SUBSTRATES FORMULATED WITH BIOSOLIDS}

ABSTRACT: The industrial and urban waste can be used as a source of nutrients to contribute not only to reduce the cost of seedling production but also to reduce or solve environmental problems. This study aimed to evaluate the use of sewage sludge as substrate on the production of seedlings of Tectona grandis. Seedlings were grown in tubes with a volumetric capacity of $280 \mathrm{~cm}^{3}$, on substrates formulated with biosolids (BIO) associated with rice hulls (CAC) or shredded coconut fiber (FC) in proportions 80:20, 60:40, 40 $60,20: 80(v: v)$, and also with 100\% of BIO, a total of nine treatment submitted to the comparison of control treatment (commercial substrate). The formed substrates were subjected to chemical and physical analysis. Ninety days after the sub culturing, the following biometrics characteristics were analyzed: shoot height, stem diameter, dry weight of shoot and root and Dickson quality index. The results indicated that the seedlings grown on substrates formulated with BIO and CAC showed the highest average height and shoot dry mass, while those produced with BIO and FC showed the highest average collar diameter. For the production of seedlings of Tectona grandis it is advised to use a substrate with proportions of 60 or $80 \%$ of biosolids when associated with coconut fiber, and $80 \%$ of biosolids when associated with rice hulls.

Keywords: sewage sludge, teak, biometric characteristics.

\section{INTRODUÇÃO}

Os resíduos sólidos urbanos vêm se constituindo em um dos grandes problemas ambientais dos últimos anos no Brasil e no mundo. O aumento populacional tem conduzido à geração de grandes quantidades de resíduos, muitos deles passíveis de reciclagem ou de reutilização, com conseqüentes benefícios ambientais, contribuindo para a preservação dos recursos naturais.

A utilização de resíduos industriais e urbanos como fonte de nutrientes pode ser uma saída efetiva não só para contribuir para a redução dos altos custos de produção, mas também são interessantes soluções para problemas ambientais.

1 Universidade Federal do Paraná - Curitiba, Paraná, Brasil

2 Universidade Federal do Espírito Santo - Alegre, Espírito Santo, Brasil
O lodo de esgoto, também chamado de biossólido, pode ser utilizado na agricultura como forma consciente de promover a reutilização destes rejeitos. Além de apresentar altos teores de matéria orgânica, macro e micronutrientes, promovem o crescimento dos organismos, melhora o nível de fertilidade e aumenta a capacidade de troca catiônica do material (GUERRINI; TRIGUEIRO, 2004; KRATZ, 2011; TRAZZI et al., 2010; TRIGUEIRO; GUERRINI, 2003). Dessa forma, esses resíduos não só podem ser utilizados para adubação de solo, mas também como componentes de substratos para produção de mudas.

A casca de arroz carbonizada e a fibra de coco também aparecem como alternativas para a formulação de substratos. A primeira, originada da carbonização da casca

Cerne, Lavras, v. 20, n. 2, p. 293-302, abr./jun. 2014 
de arroz, é extremamente leve, estéril, de fácil manuseio, de alta porosidade, boa aeração e baixa capacidade de retenção de água (COSTA, 2003; KLEIN et al., 2002). A segunda é de fácil obtenção e possui características que conferem ao substrato ótima aeração juntamente com uma boa capacidade de retenção de água e alta estabilidade física, pois se decompõe muito lentamente (NOGUERA et al., 2000; WENDLING; GATTO, 2002).

$\mathrm{O}$ substrato exerce uma influência marcante na arquitetura do sistema radicular e no estado nutricional das plantas, afetando intensamente a qualidade das mudas. Para a composição de materiais específicos, é necessária a seleção de substratos com características adequadas para cada espécie, racionalizando custos sem o comprometimento da qualidade das mudas (CALDEIRA et al., 2011).

Uma espécie com alto potencial silvicultural para produção de madeira é a teca (Tectona grandis Linn. F.). É originária das florestas decíduas mistas da Índia, Mianmar, Tailândia e Laos. Foi introduzida na Indonésia há mais de 400 anos, e hoje é extensivamente plantada não só no Sudeste Asiático, mas em toda zona tropical das Américas, África e Pacífico (FIGUEIREDO et al., 2005). Estima-se que os reflorestamentos com T. grandis, no mundo, já somam mais de três milhões de hectares, e no Brasil, a superfície plantada vem crescendo nos últimos anos, tendo atualmente pouco mais que 65 mil hectares, sendo na sua maioria localizada no estado de Mato Grosso, Amazonas, Acre e Pará (ASSOCIAÇÃO BRASILEIRA DE PRODUTORES DE FLORESTAS PLANTADAS ABRAF, 2011).

Dessa forma, o presente trabalho teve por objetivo avaliar a utilização de biossólido como componente de substrato na produção de mudas de Tectona grandis, e, diferentes proporções com fibra de coco e casca de arroz carbonizada.

\section{MATERIAL E MÉTODOS}

\subsection{Localização}

O experimento foi desenvolvido no Viveiro Florestal do Departamento de Engenharia Florestal do Centro de Ciências Agrárias da Universidade Federal do Espírito Santo - DEF/CCA-UFES, no município de Alegre, apresentando coordenadas geográficas de $20^{\circ} 45^{\prime} \mathrm{S}$ e $41^{\circ} 31^{\prime}$ $\mathrm{W}$, com altitude média de $277 \mathrm{~m}$. O clima enquadra-se no tipo Cwa (inverno seco e verão chuvoso), de acordo com a classificação de Köppen, com precipitação anual média de $1104 \mathrm{~mm}$ e temperatura média anual de $24,1^{\circ} \mathrm{C}$, com máximas diárias de $31^{\circ} \mathrm{C}$ e mínimas de $20,2^{\circ} \mathrm{C}$ (NEDTEC, 2006 citado por MAIA et al., 2007).

Cerne, Lavras, v. 20, n. 2, p. 293-302, abr./jun. 2014

\subsection{Delineamento Experimental}

Foi utilizado um delineamento experimental inteiramente casualizado, com seis repetições por tratamento, sendo cada repetição constituída por quatro plantas. Assim, cada tratamento foi representado por 24 mudas. Os dados das características analisadas foram submetidas à análise de variância e após significância do teste $F(p<0,05)$ as médias foram comparadas pelo teste Scott-Knott. Também foram obtidas comparações entre as médias por contrastes ortogonais, estabelecendo-se três contrastes: $\mathrm{C} 1=4 \mathrm{~T} 1-(\mathrm{T} 2+\mathrm{T} 3+\mathrm{T} 4+\mathrm{T} 5) ; \mathrm{C} 2=4 \mathrm{~T} 1-$ $(\mathrm{T} 6+\mathrm{T} 7+\mathrm{T} 8+\mathrm{T} 9)$ e $\mathrm{C} 3=(\mathrm{T} 2+\mathrm{T} 3+\mathrm{T} 4+\mathrm{T} 5)-(\mathrm{T} 6+$ $\mathrm{T} 7+\mathrm{T} 8+\mathrm{T} 9)$. As análises estatísticas foram realizadas através do uso do software SPSS19®.

Os substratos foram formulados com diferentes proporções de biossólido (BIO) com casca de arroz carbonizada (CAC) ou fibra de coco triturada (FC). Utilizou-se o substrato comercial florestal como tratamento testemunha (Tabela 1).

Tabela 1 - Substratos formulados (v:v) com diferentes proporções de biossólido (BIO) associado à casca de arroz carbonizada (CAC) ou à fibra de coco triturada (FC).

Table 1 - Substrates formulated ( $v: v)$ with different proportions of biosolids (BIO) associated with rice hulls (CAC) or shredded coconut fiber (FC).

\begin{tabular}{cccc}
\hline Tratamentos & BIO & CAC & FC \\
\hline T1 & 100 & - & - \\
T2 & 80 & 20 & - \\
T3 & 60 & 40 & - \\
T4 & 40 & 60 & - \\
T5 & 20 & 80 & - \\
T6 & 80 & - & 20 \\
T7 & 60 & - & 40 \\
T8 & 40 & - & 60 \\
T9 & 20 & - & 80 \\
T10 & Testemunha & \\
\hline
\end{tabular}

${ }^{1}$ Substrato comercial florestal (60\% de composto de casca de pinus, $15 \%$ de vermiculita e $25 \%$ de húmus e terra vegetal)

O biossólido utilizado no experimento foi doado pela Foz do Brasil S. A. (Estação de Tratamento de Esgoto de Cachoeiro de Itapemirim-ES). Na Tabela 2, observa-se que as quantidades de metais pesados poluentes presentes no biossólido são baixas, e de acordo com a resolução 
CONAMA - 375/2006 (BRASIL, 2006), esse material pode ser considerado adequado para uso em ambientes agrícolas.

Antes de ser utilizado na formulação dos substratos, o biossólido foi peneirado sobre malha de $3 \mathrm{~mm}$ depois de permanecer por cerca de 30 dias em ambiente aberto. A casca de arroz carbonizada e a fibra de coco triturada foram doadas pela Fibria Celulose S. A. (Unidade AracruzES). Esses materiais se apresentam prontos para serem utilizados na formulação de substratos.

Tabela 2 - Concentração total $\left(\mathrm{mg} \mathrm{dm}^{-3}\right)$ de metais pesados no biossólido realizada pela Foz do Brasil S. A.

Table 2 - Total Concentration ( $\mathrm{mg} \mathrm{dm}^{-3}$ ) of heavy metals in biosolids made by Foz do Brasil S. A.

\begin{tabular}{ccc}
\hline Parâmetros & $\begin{array}{c}\text { Resultados } \\
\text { Analíticos }\end{array}$ & $\begin{array}{c}\text { Resolução CONAMA - } \\
375 / 2006\end{array}$ \\
\hline $\mathrm{Ar}$ & $<0,5$ & 41 \\
$\mathrm{Ba}$ & 156 & 1300 \\
$\mathrm{Cd}$ & $<0,053$ & 39 \\
$\mathrm{~Pb}$ & 29 & 300 \\
$\mathrm{Cu}$ & 98 & 1500 \\
$\mathrm{Cr}$ & 26 & 1000 \\
$\mathrm{Mb}$ & 3,5 & 50 \\
$\mathrm{Ni}$ & 11 & 420 \\
$\mathrm{Se}$ & $<0,5$ & 100 \\
\hline
\end{tabular}

\subsection{Produção de Mudas}

As mudas foram produzidas entre os dias 15 de dezembro de 2009 a 15 de março de 2010, contando da repicagem até a avaliação das mesmas.

Com os substratos de cada tratamento homogeneizados, os tubetes foram preenchidos realizando leve compactação manual, de forma que o substrato se acomodasse dentro do tubetes de $280 \mathrm{~cm}^{3}$.

As mudas de teca foram produzidas a partir de sementes, cujos frutos foram obtidos através de doação da empresa Floresteca S.A. Para quebra de dormência, estes frutos foram colocados imersos em água por três noites e postos em pleno sol durantes três dias. Em seguida, os frutos foram colocados em canteiro de areia lavada para germinação.

Após atingirem altura entre cinco e sete centímetros, as plântulas foram repicadas para os tubetes, preenchidos com substratos de seus respectivos tratamentos. Os tubetes foram acondicionados em bandejas de polipropileno com capacidade de 54 tubetes, sendo estas bandejas dispostas em canteiro suspensos a $80 \mathrm{~cm}$ do solo, na casa de sombra.

As mudas permaneceram na casa de sombra durante 90 dias, irrigadas quatro vezes ao dia, por sistema de irrigação automático de microaspersão. A lâmina de irrigação diária foi de doze milímetros. Em dias de chuva, a irrigação foi interrompida. Durante esse período, não foi realizado qualquer tipo de adubação.

\subsection{Características Biométricas}

Noventa dias após a repicagem, foram avaliadas as seguintes características biométricas: a) diâmetro do coleto (D), medido na altura do colo da planta, com auxílio de um paquímetro digital; b) altura da parte aérea $(\mathrm{H})$ determinada a partir do nível do substrato até a inserção da última folha, com auxílio de uma régua graduada em milímetros; c) massa seca radicular (MSR): as raízes foram separadas da parte aérea, lavadas em peneiras e, em seguida, foram acondicionadas em sacos de papel e colocadas para secar em estufa com circulação forçada de ar, a $70^{\circ} \mathrm{C}$ até a obtenção de peso constante; d) massa seca da parte aérea (MSPA): cortado ao nível do substrato, obtido a partir do material seco em estufa com circulação forçada de ar, a $70^{\circ} \mathrm{C}$ até atingir peso constante; e) Índice de Qualidade de Dickson (IQD) (DICKSON et al., 1960 citados por FONSECA et al., 2002), calculado através da fórmula:

$\mathrm{IQD}=\mathrm{MST} /(\mathrm{H} / \mathrm{D}+\mathrm{MSPA} / \mathrm{MSR})$

\subsection{Caracterização Física e Química dos Substratos}

As análises físicas e químicas foram realizadas no Laboratório de Recursos Hídricos do Departamento de Ciências Florestais e da Madeira/CCA-UFES, em Jerônimo Monteiro, ES, segundo a metodologia da Empresa Brasileira de Pesquisa Agropecuária - EMBRAPA (1999).

Para a determinação dos componentes químicos, os substratos foram submetidos às análises antes do plantio das mudas, e assim foram determinados os teores totais de nutrientes presentes no substrato (Tabela 3).

As análises físicas corresponderam à determinação da densidade aparente do substrato (DENS), macroporosidade (MAC), microporosidade (MIC) e porosidade total ou volume total de poros (VTP). Os resultados das análises físicas realizadas podem ser observados na Tabela 4 .

Cerne, Lavras, v. 20, n. 2, p. 293-302, abr./jun. 2014 
Tabela 3 - Teores totais de macronutrientes e micronutrientes, matéria orgânica (MO) e relação C/N dos substratos formulados com biossólido.

Table 3 - Total concentrations of macronutrients and micronutrients, organic matter (MO) and C/N ratio of substrates formulated with biosolids.

\begin{tabular}{|c|c|c|c|c|c|c|c|c|c|c|c|c|c|}
\hline \multirow{2}{*}{ Tratamentos } & $\mathrm{N}$ & $\mathrm{P}$ & K & $\mathrm{Ca}$ & $\mathrm{Mg}$ & S & $\mathrm{Zn}$ & $\mathrm{Fe}$ & $\mathrm{Mn}$ & $\mathrm{Cu}$ & $\mathrm{B}$ & MO & $\mathrm{C} / \mathrm{N}$ \\
\hline & \multicolumn{6}{|c|}{--1 } & \multicolumn{7}{|c|}{ - } \\
\hline $\mathrm{T} 1-100 \% \mathrm{BIO}$ & 13,3 & 2,5 & 0,8 & 8,9 & 2,4 & 0,14 & 231 & 17480 & 157 & 53 & 8 & 65,5 & 2,9 \\
\hline $\mathrm{T} 2-80 \% \mathrm{BIO}+20 \% \mathrm{CAC}$ & 13,0 & 2,9 & 1,3 & 8,2 & 2,1 & 0,17 & 247 & 17200 & 185 & 58 & 6 & 97,2 & 4,3 \\
\hline $\mathrm{T} 3-60 \% \mathrm{BIO}+40 \% \mathrm{CAC}$ & 9,8 & 2,8 & 1,6 & 6,2 & 1,9 & 0,19 & 209 & 17280 & 184 & 43 & 6 & 130,6 & 7,7 \\
\hline $\mathrm{T} 4-40 \% \mathrm{BIO}+60 \% \mathrm{CAC}$ & 10,5 & 2,3 & 2,7 & 4,0 & 1,7 & 0,11 & 183 & 12560 & 277 & 37 & 5 & 170,4 & 9,4 \\
\hline $\mathrm{T} 5-20 \% \mathrm{BIO}+80 \% \mathrm{CAC}$ & 7,0 & 1,7 & 3,6 & 5,5 & 1,6 & 0,11 & 241 & 11040 & 322 & 28 & 16 & 241,1 & 19,9 \\
\hline $\mathrm{T} 6-80 \% \mathrm{BIO}+20 \% \mathrm{FC}$ & 11,2 & 2,3 & 1,2 & 5,5 & 1,8 & 0,14 & 225 & 15560 & 128 & 51 & 6 & 79,6 & 4,1 \\
\hline $\mathrm{T} 7-60 \% \mathrm{BIO}+40 \% \mathrm{FC}$ & 12,3 & 2,7 & 2,6 & 9,2 & 3,1 & 0,12 & 265 & 17000 & 178 & 65 & 12 & 124,8 & 5,9 \\
\hline $\mathrm{T} 8-40 \% \mathrm{BIO}+60 \% \mathrm{FC}$ & 10,5 & 2,7 & 3,1 & 7,7 & 2,6 & 0,14 & 240 & 15000 & 148 & 92 & 15 & 153,8 & 8,5 \\
\hline $\mathrm{T} 9-20 \% \mathrm{BIO}+80 \% \mathrm{FC}$ & 9,8 & 2,5 & 7,4 & 6,3 & 4,9 & 0,16 & 230 & 12080 & 158 & 64 & 24 & 151,9 & 9,0 \\
\hline T10 - Testemunha (SC) & 8,8 & 1,6 & 1,2 & 8,3 & 4,1 & 0,06 & 44 & 9200 & 199 & 10 & 14 & 145,9 & 9,6 \\
\hline Casca de arroz carbonizada (CAC) & 4,6 & 1,1 & 6,5 & 2,1 & 1,0 & 0,06 & 44 & 506 & 492 & 8 & 6 & 320,5 & 40,4 \\
\hline Fibra de coco triturada (FC) & 5,3 & 1,3 & 12,2 & 10,9 & 5,2 & 0,18 & 87 & 1130 & 78 & 50 & 50 & 213,3 & 23,3 \\
\hline
\end{tabular}

${ }^{1} \mathrm{BIO}$ - biossólido; CAC - casca de arroz carbonizada; FC - fibra de coco triturada; SC - substrato comercial.

Tabela 4 - Volume total de poros (VTP), macroporosidade (MAC), microporosidade (MIC) e densidade aparente (DENS) dos substratos formulados com biossólido.

Table 4 - Total volume of pores (VTP), macroporosity (MAC) and microporosity (MIC) and density (DENS) substrates formulated with biosolids.

\begin{tabular}{lcccc}
\hline \multicolumn{1}{c}{ Tratamentos $^{1}$} & $\begin{array}{c}\text { VTP } \\
(\%)\end{array}$ & $\begin{array}{c}\text { MAC } \\
(\%)\end{array}$ & $\begin{array}{c}\text { MIC } \\
(\%)\end{array}$ & $\begin{array}{c}\text { DENS } \\
\left(\mathrm{g} \mathrm{cm}^{-3}\right)\end{array}$ \\
\hline T1 - 100\% BIO & 64,20 & 22,51 & 41,69 & 0,58 \\
T2 - 80\%BIO + 20\%CAC & 65,21 & 23,85 & 41,36 & 0,52 \\
T3 - 60\%BIO + 40\%CAC & 67,80 & 37,40 & 30,39 & 0,47 \\
T4 - 40\%BIO + 60\%CAC & 74,18 & 49,80 & 24,39 & 0,39 \\
T5 - 20\%BIO + 80\%CAC & 72,94 & 50,38 & 22,57 & 0,33 \\
T6 - 80\%BIO + 20\%FC & 67,05 & 32,30 & 34,75 & 0,47 \\
T7 - 60\%BIO + 40\%FC & 71,75 & 20,07 & 51,68 & 0,41 \\
T8 - 40\%BIO + 60\%FC & 72,38 & 31,61 & 40,76 & 0,36 \\
T9 - 20\%BIO + 80\%FC & 75,59 & 25,82 & 49,78 & 0,24 \\
T10 - Testemunha (SC) & 75,30 & 29,65 & 45,65 & 0,32 \\
\hline
\end{tabular}

${ }^{1} \mathrm{BIO}$ - biossólido; CAC - casca de arroz carbonizada; FC - fibra de coco triturada; SC - substrato comercial.

Cerne, Lavras, v. 20, n. 2, p. 293-302, abr./jun. 2014
Para análise física foram separados três tubetes de cada tratamento, preenchidos com suas respectivas formulações. Esses substratos permaneceram na casa de sombra durante 90 dias, passando por condições iguais às que as mudas se desenvolveram. Após os 90 dias, os tubetes foram identificados, serrados com serra de arco, formando anéis de altura por volta de $5 \mathrm{~cm}$ e contidos com tecido tipo "filó" de malha fina enlaçados com elástico de borracha.

Em laboratório, os anéis foram saturados, colocados em placas de cerâmica e submetidos à pressão de $-6 \mathrm{kPa}$ no extrator de Richards, até atingir a drenagem máxima da água proporcionada por esta pressão. Os parâmetros físicos foram determinados seguindo os cálculos conforme EMBRAPA (1999).

\section{RESULTADOS E DISCUSSÃO}

\subsection{Altura da parte aérea, diâmetro do coleto e massas secas da parte aérea e radicular}

A análise de variância dos tratamentos com biossólido associado à casca de arroz carbonizada ou à fibra de coco triturada apresentou diferenças significativas, ao 
nível de 5\% de probabilidade, pelo teste F para altura da parte aérea, diâmetro do coleto, massa seca da parte aérea e massa seca radicular. As médias para estas variáveis, bem como o teste de Scott-Knott, são apresentadas na Tabela 5.

As mudas de T. grandis apresentaram valores médios de altura da parte aérea entre 10,1 e $35,9 \mathrm{~cm}$. Os tratamentos $\mathrm{T} 2(80 \% \mathrm{BIO}+20 \% \mathrm{CAC}), \mathrm{T} 3(60 \% \mathrm{BIO}+40 \% \mathrm{CAC})$ e $\mathrm{T} 4(40 \% \mathrm{BIO}+60 \% \mathrm{CAC})$ proporcionaram o maior crescimento em altura diferenciando-se estatisticamente dos demais tratamentos.

Tabela 5 - Altura da parte aérea (H), diâmetro do coleto (D), massa seca parte aérea (MSPA) e massa seca radicular (MSR) nas mudas de Tectona grandis produzidas com biossólido, noventa dias após a repicagem.

Table 5 - Shoot height (H), collar diameter (D), shoot dry mass (MSPA) and root dry mass (MSR) in seedlings of Tectona grandis grown with biosolids, ninety days after transplanting.

\begin{tabular}{|c|c|c|c|c|}
\hline Tratamento & $\begin{array}{c}\mathrm{H} \\
(\mathrm{cm})\end{array}$ & $\begin{array}{c}\mathrm{D} \\
(\mathrm{mm})\end{array}$ & $\begin{array}{l}\text { MSPA } \\
\text {--(g plar }\end{array}$ & $\begin{array}{l}\text { MSR } \\
\left(\operatorname{ta}^{-1}\right)--\end{array}$ \\
\hline $\mathrm{T} 1-100 \% \mathrm{BIO}$ & $27,4 \mathrm{~b}$ & $6,6 \mathrm{~b}$ & $4,8 \mathrm{~b}$ & $1,9 \mathrm{~d}$ \\
\hline $\mathrm{T} 2-80 \% \mathrm{BIO}+20 \% \mathrm{CAC}$ & $34,7 \mathrm{a}$ & $6,7 b$ & $7,9 \mathrm{a}$ & $3,3 \mathrm{c}$ \\
\hline $\mathrm{T} 3-60 \% \mathrm{BIO}+40 \% \mathrm{CAC}$ & $35,9 \mathrm{a}$ & $6,3 c$ & $7,6 \mathrm{a}$ & $3,2 \mathrm{c}$ \\
\hline $\mathrm{T} 4-40 \% \mathrm{BIO}+60 \% \mathrm{CAC}$ & $35,2 \mathrm{a}$ & $5,7 \mathrm{~d}$ & $6,0 \mathrm{~b}$ & $2,7 \mathrm{~d}$ \\
\hline $\mathrm{T} 5-20 \% \mathrm{BIO}+80 \% \mathrm{CAC}$ & $22,1 \mathrm{c}$ & $5,7 \mathrm{~d}$ & $2,4 \mathrm{~d}$ & $4,1 \mathrm{~b}$ \\
\hline $\mathrm{T} 6-80 \% \mathrm{BIO}+20 \% \mathrm{FC}$ & $30,3 \mathrm{~b}$ & $7,4 \mathrm{a}$ & $5,7 \mathrm{~b}$ & $4,0 \mathrm{~b}$ \\
\hline $\mathrm{T} 7-60 \% \mathrm{BIO}+40 \% \mathrm{FC}$ & $26,4 \mathrm{~b}$ & $7,4 \mathrm{a}$ & $4,8 \mathrm{~b}$ & $5,6 \mathrm{a}$ \\
\hline $\mathrm{T} 8-40 \% \mathrm{BIO}+60 \% \mathrm{FC}$ & $27,8 \mathrm{~b}$ & $7,0 \mathrm{~b}$ & $5,3 \mathrm{~b}$ & $2,4 \mathrm{~d}$ \\
\hline T9 - 20\%BIO + $80 \% \mathrm{FC}$ & $19,4 \mathrm{c}$ & $6,3 c$ & $3,5 \mathrm{c}$ & $2,0 \mathrm{~d}$ \\
\hline T10 - Testemunha (SC) & $10,1 \mathrm{~d}$ & $3,7 \mathrm{e}$ & $1,0 \mathrm{e}$ & $0,7 \mathrm{e}$ \\
\hline CV (\%) & 9,85 & 6,78 & 17,63 & 20,52 \\
\hline
\end{tabular}

${ }^{1} \mathrm{BIO}$ - biossólido; CAC - casca de arroz carbonizada; FC - fibra de coco triturada; SC - substrato comercial.

Os tratamentos $\mathrm{T} 5(20 \% \mathrm{BIO}+80 \% \mathrm{CAC})$ e T9 $(20 \% \mathrm{BIO}+80 \% \mathrm{FC})$ proporcionaram os menores crescimentos em altura comparando aos demais tratamentos constituídos com biossólido. Os tratamentos T5 e T9 apresentaram-se estatisticamente superiores apenas ao tratamento T10 (substrato comercial florestal).

Nesse sentido, nota-se que o biossólido influenciou positivamente o crescimento em altura das mudas de $T$. grandis. Os altos teores de nutrientes e matéria orgânica na composição desses resíduos (Tabela 3) contribuíram para tal fato. Teores elevados de N e P são altamente requeridos nos estádios iniciais de desenvolvimento das mudas (NEVES et al., 1990), atuando no arranque inicial do crescimento da parte aérea. De acordo com Faustino et al. (2005), o crescimento em altura está relacionado aos acréscimos de matéria orgânica no substrato.

Trabalhando com solução nutritiva completa e com omissão alternada de $\mathrm{N}, \mathrm{P}, \mathrm{K}, \mathrm{Ca}, \mathrm{Mg}$ e $\mathrm{S}$ na produção de mudas de T. grandis, Barroso et al. (2005), concluíram que o crescimento inicial das mudas foi afetado pela omissão de todos os macronutrientes, sendo os danos mais intensos e imediatos observados na ausência de $\mathrm{N}$ e Ca.

$\mathrm{O}$ teor de matéria orgânica não pode ser analisado isoladamente para indicar o crescimento em altura das mudas, já que nos tratamentos T5 $(20 \% \mathrm{BIO}+80 \% \mathrm{CAC})$, T9 $(20 \% \mathrm{BIO}+80 \% \mathrm{FC})$ e $\mathrm{T} 10$ (substrato comercial florestal), cujos teores de matéria orgânica foram tão altos quanto aos demais tratamentos, as médias de crescimento em altura foram estatisticamente inferiores aos outros tratamentos deste trabalho.

As maiores médias de diâmetro do coleto foram encontradas nos tratamentos $\mathrm{T} 6(80 \% \mathrm{BIO}+20 \% \mathrm{FC})$ e $\mathrm{T} 7$ $(60 \% \mathrm{BIO}+40 \% \mathrm{FC})$. Levando-se em consideração que as maiores médias de diâmetro do coleto foram alcançadas nos tratamentos em que o biossólido formava composto com a fibra de coco triturada, pode-se dizer que houve uma tendência de que os teores de $\mathrm{K}$ presentes na fibra de coco triturada (Tabela 3) contribuíram para o crescimento do diâmetro do coleto das mudas de $T$. grandis. $\mathrm{O} \mathrm{K}$, além de regular a abertura estomática, promove o engrossamento do caule das mudas, na fase de produção (VALERI; CORRADINI, 2005).

De acordo com Silva et al. (1997), ao trabalharem com 14 espécies florestais, concluíram que o fornecimento de $\mathrm{K}$ na fase inicial de desenvolvimento das mudas afetou positivamente no crescimento em diâmetro da maioria das espécies pioneiras e secundárias estudadas. Fato também ocorrido com o híbrido Eucalyptus urophylla $\mathrm{x}$ E. grandis em estudo com doses crescentes de K (ÁVILA, 2008). Em estudo da resposta ao crescimento de T. grandis a fertilizantes nitrogenados, fosfatados e potássicos, Abod e Siddiqui (2002) verificaram que o crescimento em diâmetro é afetado por $\mathrm{N}$ e $\mathrm{K}$, mas não pelo $\mathrm{P}$.

Os tratamentos $\mathrm{T} 4(40 \% \mathrm{BIO}+60 \% \mathrm{CAC})$ e $\mathrm{T} 5$ $(20 \% \mathrm{BIO}+80 \% \mathrm{CAC})$ proporcionaram crescimento em diâmetro estatisticamente superior apenas ao tratamento T10 (substrato comercial florestal). Fato semelhante ocorrido à Saidelles et al. (2009), que, ao trabalharem com duas espécies florestais, utilizando casca de arroz

Cerne, Lavras, v. 20, n. 2, p. 293-302, abr./jun. 2014 
carbonizada para a produção de mudas, verificaram que valores maiores que $50 \%$ de CAC proporcionaram perda no crescimento em diâmetro do coleto para tamboril (Enterolobium contortisiliquum) e garapa (Apuleia leiocarpa).

É possível observar na Tabela 3 que os valores de $\mathrm{K}$ para a casca de arroz carbonizada e para os compostos formados com esse material são altos. No entanto, nota-se que o crescimento observado para os tratamentos com esse material foi inferior aos tratamentos compostos pela fibra de coco triturada, que também apresentam altos teores de $\mathrm{K}$. É provável que as mudas produzidas nos substratos formados com a casca de arroz carbonizada não obtiveram tanto crescimento de diâmetro pelo fato deste material apresentar baixa capacidade de retenção de água, devido a uma baixa microporosidade (Tabela 4), afetando não só na disponibilidade, mas também na eficiência do fornecimento de água e nutrientes, principalmente o $\mathrm{K}$, para as plantas. Segundo Ernani et al. (2007), a lixiviação de K aumenta em razão da quantidade de água que percola no perfil. A macroporosidade (Tabela 4) proporcionada pela casca de arroz carbonizada nos tratamentos formulados com este material aumentou a percolação de água nos substratos.

As mudas de T. grandis obtiveram crescimento médio em massa seca da parte aérea entre 0,99 a 7,92 g planta $^{-1}$. As mudas produzidas nos tratamentos $\mathrm{T} 2$ e T3 $(80 \% \mathrm{BIO}+20 \% \mathrm{CAC}$ e $60 \% \mathrm{BIO}+40 \% \mathrm{CAC})$ apresentaram as maiores médias, diferenciando-se das demais. $\mathrm{O}$ tratamento testemunha (T10) foi inferior aos demais para a massa seca da parte aérea.

Os resultados expressos parecem indicar que os tratamentos formulados com biossólido propiciaram melhoria nas propriedades físicas (Tabela 4) e químicas (Tabela 3) dos substratos e, consequentemente, maiores ganhos em massa da parte aérea. Santos et al. (2008), em estudo com sete espécies arbóreas nativas, verificaram que, ao se elevar o fornecimento de P ocorreram aumentos na produção de massa seca da parte aérea para as espécies estudas. Em estudo com Pinus elliottii produzidos em diferentes substratos, Schirmer (2010) obteve os maiores valores de massa da parte aérea em substratos produzidos com biossólido e turfa fértil, conseguindo médias superiores ao tratamento testemunha com substrato comercial.

As mudas de $T$. grandis obtiveram médias de massa seca radicular variando entre 0,69 a 5,56 $\mathrm{g} \mathrm{planta}^{-1}$. O maior crescimento foi obtido no tratamento $\mathrm{T} 7(60 \% \mathrm{BIO}+40 \% \mathrm{FC})$, diferenciando-se dos demais. O tratamento testemunha (T10) foi inferior à todos para a massa seca radicular.

Cerne, Lavras, v. 20, n. 2, p. 293-302, abr./jun. 2014
De acordo com Buckeridge et al. (2004), raízes primárias e raízes jovens respiram muito intensamente e para essas raízes, o oxigênio necessário para o processo respiratório, advém do próprio substrato. Logo, existe a necessidade do substrato apresentar boa aeração, facilitando as trocas gasosas. O tratamento $\mathrm{T} 7(60 \% \mathrm{BIO}$ $+40 \% \mathrm{FC})$, assim como os tratamentos $\mathrm{T} 5(20 \% \mathrm{BIO}$ $+80 \% \mathrm{CAC})$ e $\mathrm{T} 6(80 \% \mathrm{BIO}+20 \% \mathrm{FC})$, parecem ter conferido uma interação entre características químicas (Tabela 3) e físicas (Tabela 4) que proporcional um maior crescimento radicular das mudas.

Em estudo com Senna siamea, Faustino et al. (2005), trabalhando com doses de biossólido associado terra de subsolo na produção de mudas em tubetes, constataram, sessenta dias após a semeadura, que a maior em massa seca radicular foi obtida no tratamento com $75 \%$ de BIO. Trigueiro e Guerrini (2003), testando biossólido com casca de arroz carbonizada na produção de mudas de eucalipto, verificaram que os tratamentos com 50 e $60 \%$ de biossólido apresentaram os maiores ganhos em massa radicular, não diferenciando do tratamento testemunha (substrato comercial). Cunha et al. (2006), avaliando o efeito de diferentes substratos sobre o crescimento de mudas de Acacia sp. verificaram que o substrato composto de biossólido em sua totalidade proporcionou maior crescimento nas mudas de $A$. mangium e A. auriculiformis no acúmulo de massa seca radicular.

Apesar das diferenças entre os tratamentos evidenciadas pelo teste de média de Skott-Knott, optouse por avaliar também a influência da casca de arroz carbonizada e da fibra de coco triturada como componentes do substrato, conforme contrastes expressos na Tabela 6.

Tabela 6 - Média das diferenças entre os contrastes ortogonais para altura da parte aérea $(\mathrm{H})$, diâmetro do coleto (D), massa seca da parte aérea (MSPA), massa seca radicular (MSR) e índice de qualidade de Dickson (IQD) nas mudas de Tectona grandis produzidas com biossólido, noventa dias após a repicagem.

Table 6 - Average of the differences between the orthogonal contrasts for shoot height $(H)$, collar diameter $(D)$, shoot dry matter (MSPA), root dry mass (MSR) and Dickson quality index (IQD) on seedlings Tectona grandis grown with biosolids, ninety days after transplanting.

\begin{tabular}{ccccc}
\hline Contrastes & ALT & DIAM & MSPA & MSR \\
\hline C1 & $-18,39^{* *}$ & $2,13^{* *}$ & $-4,71^{\star *}$ & $-5,68^{* *}$ \\
C2 & $5,60^{\text {ns }}$ & $-1,47^{\text {ns }}$ & $-0,12^{\text {ns }}$ & $-6,42^{* *}$ \\
C3 & $23,99^{* *}$ & $-3,60^{* *}$ & $4,59^{* *}$ & $0,74^{\text {ns }}$ \\
\hline
\end{tabular}

$\mathrm{C} 1=4 \mathrm{~T} 1-(\mathrm{T} 2+\mathrm{T} 3+\mathrm{T} 4+\mathrm{T} 5) ; \mathrm{C} 2=4 \mathrm{~T} 1-(\mathrm{T} 6+\mathrm{T} 7+\mathrm{T} 8+\mathrm{T} 9)$ e $\mathrm{C} 3$ $=(\mathrm{T} 2+\mathrm{T} 3+\mathrm{T} 4+\mathrm{T} 5)-(\mathrm{T} 6+\mathrm{T} 7+\mathrm{T} 8+\mathrm{T} 9)$. ns Não significativo. ${ }^{*}$ Significativo a $1 \%$ de probabilidade pelo teste $\mathrm{F}$. 
No contraste $\mathrm{C} 1$, onde o substrato formado apenas com biossólido é comparado aos substratos com a casca de arroz carbonizada, é possível observar que para todas as características biométricas avaliadas as diferenças foram significativas. A altura da parte aérea, a massa seca radicular e a massa seca da parte aérea foram superiores nos substratos formulados com a casca de arroz carbonizada, no entanto, o diâmetro do coleto foi maior para o substrato com $100 \%$ de biossólido.

Comparando os substratos formulados com fibra de coco triturada ao formulado apenas com biossólido, podese notar no contraste $\mathrm{C} 2$ que apenas a massa seca radicular apresentou resultados significativos, sendo superior para os substratos com fibra de coco.

No contraste C3, comparando-se os substratos formulados com casca de arroz carbonizada aos substratos formulados com fibra de coco triturada, apenas a massa seca radicular não apresentou diferenças significativas. A altura e a massa seca da parte aérea foram superiores para os tratamentos com casca de arroz carbonizada, enquanto que o diâmetro do coleto foi estatisticamente maior para os substratos com fibra de coco triturada.

De uma forma geral, os três contrastes avaliados evidenciaram a influência da casca de arroz carbonizada no crescimento da parte aérea das mudas (altura e massa seca), enquanto que a maior influência da fibra de coco triturara está relacionada ao crescimento em diâmetro das mudas.

\section{2 Índice de qualidade de Dickson (IQD)}

De acordo com Fonseca et al. (2002), o índice de qualidade de Dickson é um bom indicador da qualidade das mudas, pois no seu cálculo são consideradas as robustez e o equilíbrio da distribuição da biomassa na muda, ponderando os resultados de vários parâmetros importantes empregados para avaliação da qualidade.

Os valores de índice de qualidade de Dickson para as mudas de $T$. grandis variaram entre 0,40 e 2,34 (Figura 1). Todos os tratamentos com biossólido resultaram em mudas com qualidade superior à testemunha. A maior média foi obtida no tratamento $\mathrm{T} 7(60 \% \mathrm{BIO}+40 \% \mathrm{FC})$, diferenciando-se estatisticamente dos demais tratamentos. Os tratamentos com $80 \%$ de biossólido (T2 e T6), e com $80 \%$ de casca de arroz carbonizada (T5) também apresentaram um equilíbrio na distribuição da biomassa das mudas.

Estudos na literatura mostram que o Índice de Qualidade de Dickson é um parâmetro variável, influenciado principalmente em função da espécie, do manejo das mudas no viveiro, do tipo e proporção do substrato, do volume do recipiente e de acordo com a idade em que muda foi avaliada (CRUZ et al., 2006; MALAVASI; MALAVASI, 2006; SCHIRMER, 2010). Por

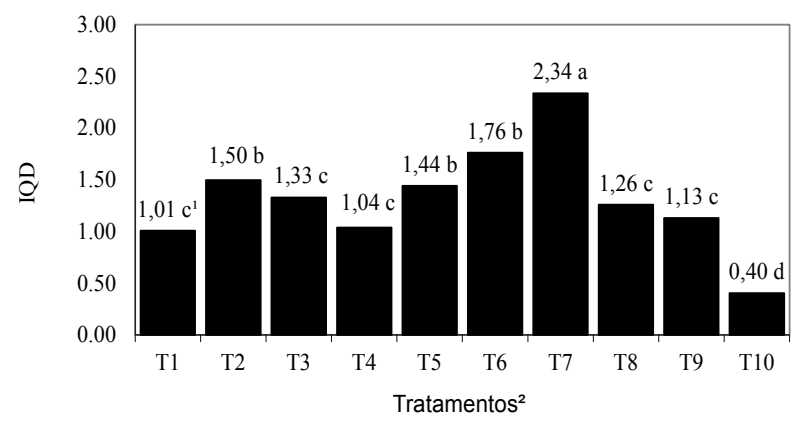

Figura 1 - Índice de qualidade de Dickson (IQD) nas mudas de Tectona grandis produzidas em substratos formulados com biossólido, noventa dias após a repicagem.

Figure 1 - Dickson quality index (IQD) in seedlings of Tectona grandis grown on substrates formulated with biosolids, ninety days after transplanting.

${ }^{1}$ Médias seguidas da mesma letra, na coluna, não diferem estatisticamente entre si pelo teste de Scott-Knott $(\mathrm{P}>0,05)$. ${ }^{2} \mathrm{BIO}$ (biossólido), CAC (casca de arroz carbonizada), FC (fibra de coco triturada): T1 - 100\%BIO, T2 - 80\%BIO+20\%CAC, T3 - 60\%BIO+40\%CAC, T4 - 40\%BIO+60\%CAC, T5 - 20\%BIO+80\%CAC, T6 - 80\%BIO+20\%FC, T7 - 60\%BIO+ $40 \% \mathrm{FC}, \mathrm{T} 8-40 \% \mathrm{BIO}+60 \% \mathrm{FC}$, T9 - 20\%BIO+80\%FC, T10 Testemunha (substrato comercial).

isso é importante que a comparação seja realizada apenas dentro de um mesmo trabalho.

\section{CONCLUSÕES}

As mudas produzidas nos substratos formulados com biossólido e casca de arroz carbonizada apresentaram as maiores médias de altura e massa seca da parte aérea, enquanto que as produzidas com biossólido e fibra de coco obtiveram as maiores médias de diâmetro do coleto.

Para a produção de mudas de Tectona grandis, é aconselhável a utilização de um substrato com proporções de 60 ou $80 \%$ de biossólido quando associado à fibra de coco triturada; e de $80 \%$ de biossólido quando associado à casca de arroz carbonizada.

Cerne, Lavras, v. 20, n. 2, p. 293-302, abr./jun. 2014 


\section{AGRADECIMENTOS}

Os autores são gratos à CAPES e ao CNPq pela concessão de bolsas de estudo e pesquisa. À Fibria S.A, à Floresteca S.A. e à Foz do Brasil S.A. pelas doações de substratos, dos frutos de teca e do biossólido, respectivamente.

\section{REFERÊNCIAS}

ABOD, S. A.; SIDDIQUI, M. T. Growth response of teak (Tectona grandis L.f.) seedlings to nitrogen, phosphorus and potassium fertilizers. Pertanika Journal of Tropical Agricultural Science, Selangor, v. 25, n. 2, p. 107-113, 2002.

ASSOCIAÇÃO BRASILEIRA DE PRODUTORES DE FLORESTAS PLANTADAS. Anuário estatístico da ABRAF: ano base 2010. Brasília, 2011. 130 p.

ÁVILA, F. S. d'. Efeito do fósforo, nitrogênio e potássio na produção de mudas clonais de eucalipto. 2008. 62 f. Dissertação (Mestrado em Ciência Florestal) - Universidade Federal de Viçosa, Viçosa, 2008.

BARROSO, D. G.; FIGUEIREDO, F. A. M. M. A.; PEREIRA, R. C.; MENDONÇA, A. V. R.; SILVA, L. C. Diagnóstico de deficiências de macronutrientes em mudas de teca. Revista Árvore, Viçosa, v. 29, n. 5, p. 671-679, set./out. 2005.

BRASIL. Ministério do Meio Ambiente. Resolução CONAMA n. 375, de 29 de agosto de 2006. Define critérios e procedimentos, para o uso agrícola de lodos de esgoto gerados em estações de tratamento de esgoto sanitário e seus produtos derivados, e dá outras providências. Brasília, 2006. Disponível em: $<\mathrm{http}: / /$ www.mma.gov.br/port/conama/res/res06/res37506.pdf>. Acesso em: 10 mar. 2012.

BUCKERIDGE, M. S.; TINÉ, M. A. S.; MINHOTO, M. J.; LIMA, D. U. Respiração. In: KERBAUY, G. B. (Ed.). Fisiologia vegetal. Rio de Janeiro: Guanabara Koogan, 2004. p. 198-216.

CALDEIRA, M. V. W.; WENDLING, I.; PENCHEL, R. M.; GONÇALVES, E. O.; KRATZ, D.; TRAZZI, P. A. Propriedades de substratos para produção de mudas florestais. In: CALDEIRA, M. V. W.; GARCIA, G. O.; GONÇALVES, E. O.; ARANTES, M. D. C.; FIEDLER, N. C. (Ed.). Contexto e perspectivas da área florestal no Brasil. Visconde do Rio Branco: Suprema, 2011. v. 1, p. 142-160.

COSTA, A. M. G. Substrato e adubação mineral na formação de porta-enxerto de gravioleira (Anonna muricata L.) em tubete. 2003. 45 f. Dissertação (Mestrado em Fitotecnia) - Universidade Federal do Ceará, Fortaleza, 2003.

CRUZ, C. A. F.; PAIVA, H. N.; GUERRERO, C. R. A. Efeito da adubação nitrogenada na produção de mudas de sete-cascas (Samanea inopinata (Harms) Ducke). Revista Árvore, Viçosa, v. 30, n. 4, p. 537-546, jul./ago. 2006.

CUNHA, A. M.; CUNHA, G. M.; SAMENTO, R. A.; CUNHA, G. M.; AMARAL, J. F. T. Efeito de diferentes substratos sobre o desenvolvimento de mudas de Acacia sp. Revista Árvore, Viçosa, v. 30, n. 1, p. 207-214, jan./ fev. 2006.

EMPRESA BRASILEIRA DE PESQUISA AGROPECUÁRIA. Manual de análises químicas de solos, plantas e fertilidade. Rio de Janeiro, 1999. 370 p.

ERNANI, P. R.; ALMEIDA, J. A.; SANTOS, F. C. Potássio. In: NOVAIS, R. F.; ALVAREZ, V. H.; BARROS, N. F.; FONTES, R. L. F.; CANTARUTTI, R. B.; NEVES, J. C. L (Ed.). Fertilidade do solo. Viçosa, MG: Sociedade Brasileira de Ciência do Solo, 2007. p. 551-594.

FAUSTINO, R.; KATO, M. T.; FLORÊNCIO, L.; GAVAZZA, S. Lodo de esgoto como substrato para produção de mudas de Senna siamea Lam. Revista Brasileira de Engenharia Agrícola e Ambiental, Campina Grande, v. 9, p. 278-282, 2005.

FIGUEIREDO, E. O.; OLIVEIRA, L. C.; BARBOZA, L. K. Teca (Tectona grandis L.f.): principais perguntas do futuro empreendedor florestal. Rio Branco: EMBRAPA Acre, 2005.

FONSECA, E. P.; VALÉRI, S. V.; MIGLIORANZA, E.; FONSECA, N. A. N.; COUTO, L. Padrão de qualidade de mudas de Trema micrantha (L.) Blume, produzidas sob diferentes períodos de sombreamento. Revista Árvore, Viçosa, v. 26, p. 515-523, 2002.

GUERRINI, I. A.; TRIGUEIRO, R. M. Estudo das características físicas e químicas de substratos compostos por biossólidos e casca de arroz carbonizada.

Cerne, Lavras, v. 20, n. 2, p. 293-302, abr./jun. 2014 
Revista Brasileira de Ciência do Solo, Viçosa, v. 28, n. 6, p. 1069-1076, 2004.

KLEIN, V. A.; CAMARA, R. K.; SIMON, M. A.; DIAS, S. T. Casca de arroz carbonizada como condicionador de substrato. In: FURLANI, A. M. C. (Ed.).

Caracterização, manejo e qualidade de substratos para produção de plantas. Campinas: Instituto Agronômico, 2002. p. 95. (Documentos IAC, 70).

KRATZ, D. Substratos renováveis na produção de mudas de Eucalyptus benthamii Maiden et Cambage e Mimosa scabrella Benth. 2011. 121 f. Dissertação (Mestrado em Ciências Florestais) - Universidade Federal do Paraná, Curitiba, 2011.

MAIA, A. R.; LOPES, J. C.; TEIXEIRA, C. O. Efeito do envelhecimento acelerado na avaliação da qualidade fisiológica de sementes de trigo. Ciência e Agrotecnologia, Lavras, v. 31, n. 3, p. 678-684, maio/ jun. 2007.

MALAVASI, U. C.; MALAVASI, M. M. Efeito do volume do tubete no crescimento inicial de plântulas de Cordia trichotoma (Vell.) Arrab. ex Steud e Jacaranda micranta Cham. Ciência Florestal, Santa Maria, v. 16, n. 1, p. 11-16, 2006.

NEVES, J. C. L.; GOMES, J. M.; NOVAIS, R. F. Fertilização mineral de mudas de eucalipto. In: BARROS, N. F.; NOVAIS, R. F. (Ed.). Relação soloeucalipto. Viçosa, MG: Folha de Viçosa, 1990. p. 100124.

NOGUERA, P.; ABAD, M.; NOGUERA, V.; PUCHADES, R.; MAQUIEIRA, A. Coconut coir waste, a new and viable ecologically-friendly peat substitute. Acta Horticulturae, The Hague, v. 517, p. 279-286, 2000 .

SAIDELES, F. L. F.; CALDEIRA, M. V. W.; SCHIRMER, W. N.; SPERANDIO, H. V. Casca de arroz carbonizada como substrato para produção de mudas de tamboril-da-mata e garapeira. Revista Ciências Agrárias, Londrina, v. 30, p. 1173-1186, 2009.

SANTOS, J. Z. L.; RESENDE, A. V.; CORTE, E. F. Crescimento, acúmulo de fósforo e frações fosfatadas em mudas de sete espécies arbóreas nativas. Revista Árvore, Viçosa, v. 32, n. 5, p. 799-807, set./out. 2008.

SCHIRMER, G.K. Utilização do lodo de esgoto na vermicompostagem e como substrato para a produção de mudas de Pinus elliottii Engelm. 2010. 93f. Dissertação (Mestrado em Ciência do Solo) Universidade Federal de Santa Maria, Santa Maria, 2010.

SILVA, I. R.; FURTINI NETO, A. E.; CURI, N.; VALE, F. R. Crecimento inicial de quatorze espécies florestais nativas em resposta à adubação potássica. Pesquisa Agropecuária Brasileira, Brasília, v. 32, n. 2, p. 205 212, 1997.

TRAZZI, P. A.; CALDEIRA, M. V. W.; COLOMBI, R. Avaliação de mudas de Tecoma stans utilizando biossólido e resíduo orgânico. Revista de Agricultura, Piracicaba, v. 85, p. 218-226, 2010.

TRIGUEIRO, R. M.; GUERRINI, I. A. Utilização de biossólido como substrato para produção de mudas de eucalipto. Scientia Forestalis, Piracicaba, n. 64, p. 1123, 2003.

VALERI, S. V.; CORRADINI, L. Fertilização em viveiros para a produção de mudas de Eucalyptus e Pinus. In: GONÇALVES, J. L. M.; BENEDETTI, V. (Ed.). Nutrição e fertilização florestal. Piracicaba: Instituto de Pesquisas e Estudos Florestais, 2005. p. 167-190.

WENDLING, I.; GATTO, A. Substratos, adubação e irrigação na produção de mudas. Viçosa, MG: Aprenda Fácil, 2002.

Recebido: 23 de fevereiro de 2011; aceito: 05 de setembro de 2013. 
